\title{
Facilitation of equivalence - equivalence responding: generalization of relational responses
}

\author{
Facilitación de la respuesta de equivalencia - equivalencia: generalización de respuestas \\ relacionales
}

\author{
Vicente Perez \\ Universidad Nacional de Educación a Distancia \\ Andres Garcia \\ Universidad Hispalense \\ Jesus Gomez. \\ Universidad de Huelva
}

\begin{abstract}
Equivalence-equivalence responding (Eq-Eq) has become a behaviour analytic model of analogical reasoning. In previous works it was demonstrated that the exposition to a non-arbitrary relational task (facilitation procedure) improves performance in Eq-Eq tasks. In the present work we attempted to analyze the role of task components: arbitrary or nonarbitrary relational responses, role as sample or comparisons, and relating relations. In the first experiment, we devised fo ur facilitation procedures combining two dimensions: simple or compound sample or comparisons and arbitrary or nonarbitrary relations among compound stimuli. In the second experiment two facilitation procedures including compound stimuli were tested. In one condition arbitrary relations worked as sample, and non-arbitrary relations as comparison. In the other condition its function was reversed. All procedures were effective to improve $\mathrm{Eq}-\mathrm{Eq}$ to different extents, being arbitrary relational responses the key element. These results show generalization between non-arbitrary and arbitrary responses, and add further support to Eq-Eq responding as operant behaviour.
\end{abstract}

Key words: Equivalence-equivalence; analogical reasoning; matching to sample; compound stimuli; adults .

\section{RESUMEN}

El paradigma experimental de equivalencia - equivalencia (Eq-Eq) se ha convertido en un modelo analítico conductual de razonamiento analógico. En trabajos anteriores se demostró que la exposición a un procedimiento de facilitación con relaciones no arbitrarias mejoraba la ejecución en las pruebas de Eq-Eq. En el presente trabajo tratamos de analizar el papel de los componentes de la tarea de Eq-Eq: respuestas relacionales arbitrarias o no arbitrarias, función como muestra o comparación y relacionar relaciones. En el primer experimento se diseñaron cuatro procedimientos de facilitación combinando dos dimensiones: muestras o comparaciones compuestas y relaciones arbitrarias o no arbitrarias entre los elementos del compuesto. En el segundo experimento se pusieron a prueba dos procedimientos de facilitación con estímulos compuestos. En la primera condición, la muestra mantenía una relación arbitraria y las comparaciones no-arbitraria; en la segunda condición los papeles fueron invertidos. Todos los procedimientos fueron efectivos en distinto grado para facilitar $\mathrm{Eq}-\mathrm{Eq}$, siendo las relaciones arbitrarias el elemento fundamental. Estos resultados muestran generalización entre relaciones no arbitrarias y arbitrarias, añadiendo evidencia a favor de la conceptualización de las relaciones de Eq-Eq como conducta operante.

Palabras clave: Equivalencia-equivalencia; razonamiento analógico; igualación a la muestra; estímulos compuestos; adultos.

Artículo recibido/Article received: Agosto 12 2011/August 132011, Artículo aceptado/Article accepted: Noviembre 12 2011/November 12 2011 Dirección correspondencia/Mail Address:

Vicente Pérez Fernández, Departamento de Psicología Básica I, Facultad de Psicología, Universidad Nacional de Educación a Dis tancia. Juan del Rosal, 10. Ciudad Universitari 28040 Madrid, Spain.E-mail: vperez@psi.uned.es

INTERNATIONAL JOURNAL OF PSYCHOLOGICAL RESEARCH esta incluida en PSERINFO, CENTRO DE INFORMACION PSICOLOGICA DE COLOMBIA, OPEN JOURNAL SYSTEM, BIBLIOTECA VIRTUAL DE PSICOLOGIA (ULAPSY-BIREME), DIALNET y GOOGLE SCHOLARS. Algunos de sus articulos aparecen en SOCIAL SCIENCE RESEARCH NETWORK y está en proceso de inclusion en diversas fuentes y bases de datos internacionales. INTERNATIONAL JOURNAL OF PSYCHOLOGICAL RESEARCH is included in PSERINFO, CENTRO DE INFORMACIÓN PSICOLÓGICA DE COLOMBIA, OPEN JOURNAL SYSTEM, BIBLIOTECA VIRTUAL DE PSICOLOGIA (ULAPSY-BIREME), DIALNET and GOOGLE SCHOLARS. Some of its articles are in SOCIAL SCIENCE RESEARCH NETWORK, and it is in the process ofinclusion in a variety of sources and international databases. 
International Journal of Psychological Research, 2011. Vol. 4. No. 2. ISSN impresa (printed) 2011-2084

ISSN electrónica (electronic) 2011-2079

Recent decades witnessed a growing interest in the theoretical explanation and empirical extension of derived or non explicitly reinforced behaviour (e. g. Gómez, García, Pérez, Gutiérrez, y Bohórquez, 2004; Luciano y Gómez, 2001; O'Toole, Barnes-Holmes, Murphy, O'Connor, \& Barnes-Holmes, 2009). Murray Sidman (1971; Sidman \& Tailby, 1982) showed that when verbal humans learned different arbitrary conditional discriminations sharing common elements (e. g., A-B and B-C), they could later relate those stimuli in untrained but predictable ways. Explaining equivalence relations and its connection with human language and cognition is a central topic of modern behaviour analytic proposals (e. g. Hayes, Barnes-Holmes \& Roche, 2001; Horne \& Lowe, 1996; Sidman, 1994), and the systematic study of behaviour derived after conditional discriminations in increasingly complex situations is linking many basic psychological phenomena to complex human functioning.

Analogical reasoning has been one of the typically human abilities addressed within this framework (e. g. Carpentier, Smeets, \& Barnes-Holmes, 2002; Lipkens \& Hayes, 2009; Ruiz \& Luciano, 2011; Stewart \& BarnesHolmes, 2009; Stewart, Barnes-Holmes, Roche, \& Smeets, 2001, 2002a). See Stewart \& Barnes-Holmes (2004) for a review. Extending previous studies about equivalence relations involving complex samples and comparisons (e. g. Markham \& Dougher, 1993; Pérez-González, 1994; Stromer \& Stromer, 1990), Barnes, Hegarty and Smeets (1997) proved that, after the relations among simple elements were taught, human adults and a 9 year old child could relate arbitrary relations in a non reinforced matching to sample task. In the first phase, the authors trained the conditional discriminations needed to derive four three member equivalence classes (A1-B1-C1, A2-B2-C2, A3$\mathrm{B} 3-\mathrm{C} 3$ and A4-B4-C4). In the second phase, with no feedback, pairs of equivalent or non-equivalent stimuli were used as sample and comparisons. For example, in the presence of sample $\mathrm{B} 1 \mathrm{C} 1$ participants reliably choose $\mathrm{B} 3 \mathrm{C} 3$ as comparison instead of $\mathrm{B} 3 \mathrm{C} 4$ (equivalence-equivalence), while in the presence of sample $\mathrm{B} 1 \mathrm{C} 2$, comparison $\mathrm{B} 3 \mathrm{C} 4$ was chosen (non-equivalence-non-equivalence). This behaviour (relating relations) was generally labelled as Equivalence-Equivalence (Eq-Eq). For example, apple and orange are equivalent in the context "fruit", as helm and steering wheels are equivalent in the context "used to drive".

Barnes et. al. (1997, p. 59) proposed that Eq-Eq responding could be viewed as overarching or generalized operant behaviour, as described in relational frame theory or RFT (Hayes et al., 2001). In a nutshell, a generalized operant is the result of multiple exemplar training involving different stimulus and situations, and thus can be arbitrarily applied to an unlimited number of instances despite their formal properties. Generalised operants can be brought
Perez, V., Garcia, A., \& Gomez, J. (2011). Facilitation of the equivalence equivalence responding: generalization of relational responses. International Journal of Psychological Research, 4(2), 20-29.

under contextual control, so that an appropriate cue (discriminative stimulus) establishes the occasion to apply it to any particular instance. This conceptualisation appears to be empirically testable, since the features attributed to overarching or generalised operants are exactly the same of "traditional" or simple operant behaviour (Skinner, 1938). (See Hayes \& Barnes-Holmes, 2004; Hayes et al., 2001). RFT authors also stress the relevance of two basic behaviour analytic principles: 1) stimulus classes controlling behaviour should be functionally defined, and 2) a relation among stimuli or events can function as a discriminative stimuli (Hayes, Gifford, \& Wilson, 1996).

Regarding the first claim, if relating relations is an operant class of responses, its basic behavioural principles should remain valid in the case of $\mathrm{Eq}-\mathrm{Eq}$ responding. Several properties of operant behaviour have been demonstrated in Eq-Eq responding. For example, contextual control of Eq-Eq responding was assessed in the Barnes et. al. (1997) original work (Experiment 3), and some other basic phenomena as blocking or overshadowing among relations have been also demonstrated (Bohórquez, García, Gutiérrez, Gómez, y Pérez, 2002; García, Bohórquez, Gómez, Gutiérrez, y Pérez, 2001; García, Bohórquez, Pérez, Gutiérrez, y Gómez, 2008; García, Gutiérrez, Bohórquez, Gómez, y Pérez, 2002). Proving generalization would add further evidence to this view.

As for the second claim, a great deal of empirical research conducted showed strong evidence for relational control in conditional discriminations in both nonhumans (e. g. Sweeney \& Urcuioli, 2010; Vasconcelos, 2008; Wright \& Katz, 2007) and humans in more complex designs (e. g. Pérez-González, 1994; see details below). Regarding Eq-Eq responding, developmental studies suggest that relational stimulus control could be a prerequisite for Eq-Eq responding (Carpentier et al., 2002; Carpentier, Smeets \& Barnes-Holmes, 2003; García et al. (2011); Pérez, García, Gómez, Bohórquez, \& Gutiérrez, 2004). Eq-Eq responding as well as classic analogies appear to involve relational responses to both arbitrary and non arbitrary components; for example, apples and oranges are equivalent in the context fruits, but they also share nonarbitrary features, as shape and size (Stewart, BarnesHolmes, Roche, \& Smeets, 2002b). In adults, a previous work (Pérez, García, \& Gómez, 2011) showed that the exposition to a non-arbitrary relational task improved subsequent Eq-Eq tests. This task, called "same/different" or S/D, consisted in a matching to sample task with compound stimuli. The sample could be formed by two identical or different familiar geometric figures (e.g., D1D1 or D2D3), while one of the comparisons was always formed by identical figures (e.g., F1F1) and the other by different figures (e.g. F2F3). The exposition to this 
International Journal of Psychological Research, 2011. Vol. 4. No. 2. ISSN impresa (printed) 2011-2084

ISSN electrónica (electronic) 2011-2079

facilitation procedure after baseline training and testing improved the performance in a subsequent Eq-Eq test.

As adult participants presumably learned the necessary relational skills before arriving to the experimental situation, these results support the hypothesis that reinforcing an instance of a (non-arbitrary) relational response increases the probabilities that other (arbitrary) relational features of the stimuli function as discriminative stimuli. Therefore, the lack of relational stimulus control appears to be a plausible explanation of Eq-Eq test failures in this population. Nevertheless, the facilitative effect found in that work was moderate: only $13 / 32$ participants $(40.6 \%)$ showed Eq-Eq responding after the non-arbitrary facilitation task (but none without it). The present research focus on extending these results by 1) creating further facilitation procedures promoting the $\mathrm{Eq}-\mathrm{Eq}$ responding: if relating arbitrary relations $(\mathrm{Eq}-\mathrm{Eq})$ is a generalised operant, the more similarity between the relations presented in the facilitation procedure and the $\mathrm{Eq}-\mathrm{Eq}$ test situation, the more improvement should be expected (i.e., generalization between relational, functionally defined stimulus classes), and 2) analyzing the role of arbitrary and non-arbitrary relational stimuli as sample or comparison. Two experiments were designed with these goals.

\section{EXPERMENT 1}

One of the hypotheses proposed as an explanation of unsuccessful Eq-Eq derivation in adult participants is that they might guide their behaviour by individual stimuli (Carpentier et al., 2002, 2003; Pérez et al., 2004). Previous studies showed that non-relational and non-arbitrary features of sample and comparisons can prevent relational stimulus control in Eq-Eq tasks (Bohórquez et al., 2002; García et al., 2001; García et al., 2008; García, Gómez, Pérez, Bohórquez, \& Gutiérrez, 2003; García et al., 2002). Therefore, ensuring relational control by compound samples and comparisons could help us to develop better training conditions for $\mathrm{Eq}-\mathrm{Eq}$ responding and to understand the behavioural processes underlying this complex behavior. A pioneering study on relational stimulus control may serve as starting point. In 1994, Pérez-González carried out the first study showing that an arbitrary relation could be used as discriminative stimulus in a complex conditional discrimination. His procedure was divided in three phases. First, he trained three conditional discriminations, A1-B1, A2-B2 and A3-B3 (AB relations; analogous PQ relations were also trained). Second, he trained a "yes/no" - like discrimination involving novel X stimuli (AB-X relations). For example, in the presence of sample A1B1, selecting $\mathrm{X} 1$ was reinforced, while in the presence of $\mathrm{A} 2 \mathrm{~B} 3, \mathrm{X} 2$ was the reinforced comparison. Third, the transference of this discrimination was assessed
Perez, V., Garcia, A., \& Gomez, J. (2011). Facilitation of the equivalence equivalence responding: generalization of relational responses. International Journal of Psychological Research, 4(2), 20-29.

in a non-reinforced test using the PQ relations. Participants reliably selected comparis on $\mathrm{X} 1$ in the presence of class member samples (e. g. P1Q1) and X2 when non class members appeared as sample (e. g. P2Q3). Transference to a novel situation in phase 3 ruled out the alternative interpretation of sample elements acting as a compound.

A similar procedure was introduced by Carpentier et al. (2003) to increase the probability of an Eq-Eq response in five year old children, although with several differences with the present study. First, an Eq-Eq baseline was not established before introducing this procedure, and thus participants would have responded correctly before the introduction of the facilitation procedures. Second, the facilitative effect (found in only one of the participants, who passed Eq-Eq evaluation) cannot be unequivocally attributed to this manipulation, since the same child was exposed to a combination of procedures. In the present experiment, a procedure called "Discrimination of relations" (DR) was introduced to increase the salience of the relations among stimuli. We established an Eq-Eq baseline, based in Pérez et al. (2011), and then manipulated the type of relation (arbitrary or non-arbitrary) and its role in the procedure (sample or comparison). Baseline testing was introduced to ensure the failure of the participant in the first place; only one facilitation procedure was introduced in each condition in order to separately assess its effect. Besides, the training and testing procedure replicates that of Pérez et al., (2011) which proved to rule out learning without explicit reinforcement during Eq-Eq testing (Pérez \& García, 2009, 2010).

\section{Participants}

\section{METHOD}

Fifty seven participants participated in this experiment, 47 women and 10 men ranging from 18 to 49 years of age $($ mean $=29.96$; standard deviation $=7.5$ ). They were volunteer university students and had no previous knowledge of the purpose of the experiment. Subjects were randomly as signed to four conditions: Thirteen participants were assigned to condition DRa (2 men, 11 women); 14 to condition DRb (3 man, 11 women); 13 to condition DRc (4 men, 9 women) and 13 to condition 4 (1 man, 12 women).

Our goal was to count with at least eight valid participants in each experiment. A valid participant was defined as one who successfully passed the conditional discrimination training and the equivalence test but failed the first Eq-Eq evaluation.

\section{Apparatus and stimuli}

The whole procedure was designed with Macromedia Flash MX. The application displayed stimuli and consequences, and also recorded responses. Stimuli 
International Journal of Psychological Research, 2011. Vol. 4. No. 2.

ISSN impresa (printed) 2011-2084

ISSN electrónica (electronic) 2011-2079

(see Figure 1) were images specifically designed for this experimental series.

Figure 1. Experiment 1. Stimuli used. Top: Black / White stimuli used in training, Eq-Eq evaluation and DRa and DRb procedures. Bottom: Geometric coloured shapes used in the facilitation procedures DRc and DRd. $R=\operatorname{Red} ; G=$ Green; $Y=$ Yellow; $P=$ Pink; P.b. = Pale blue; D. $b .=$ Dark blue; $B r=$ Brown; $B l=$ Black.
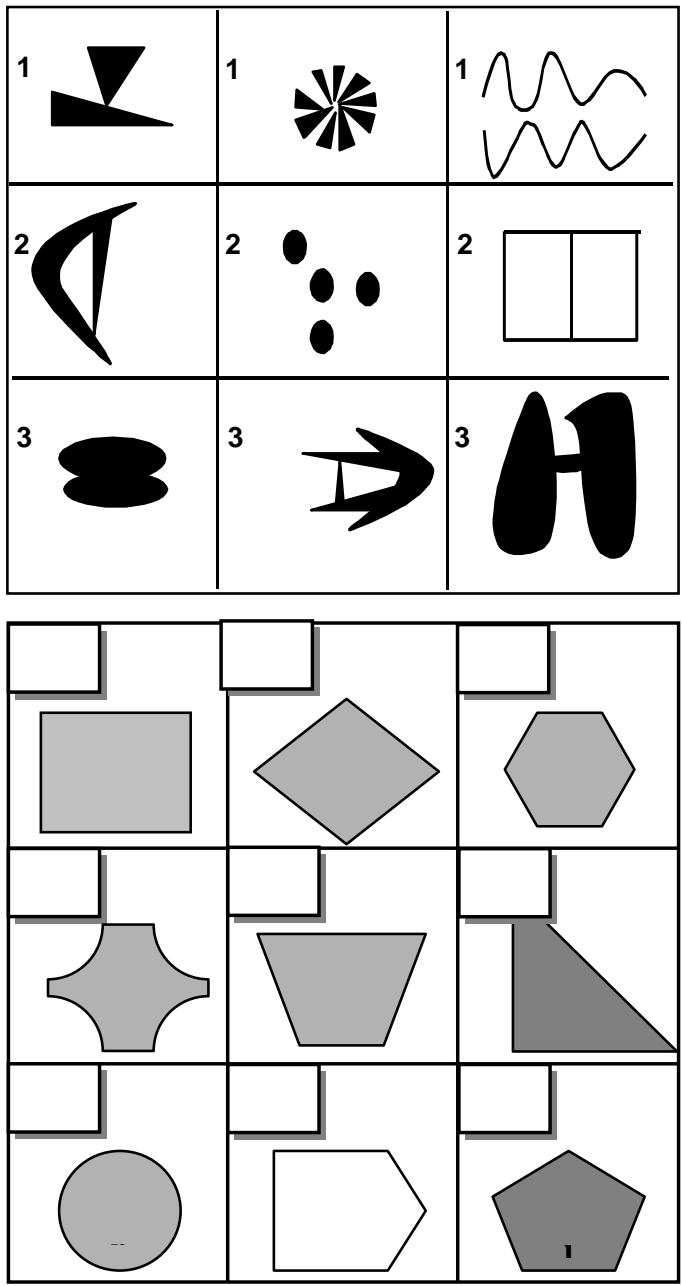

The general procedure consisted in an arbitrary matching to sample with an observation response to the sample. When the response was consistent with the arranged relation among stimuli, the message "GOOD" ("BIEN" in Spanish) was presented for $1.4 \mathrm{sec}$. in a green background, and next trial begun. If the response was not consistent, the message presented in a red background was "NO, you made ... errors. The maximum permitted is ..." and the same trial started again.

Figure 2. Experiment 1. Standard sequence of trials and consequences. Top left: sample stimuli. Top right: sample (bottom) and comparison stimuli (top). Bottom left: positive
Perez, V., Garcia, A., \& Gomez, J. (2011). Facilitation of the equivalence equivalence responding: generalization of relational responses. International Journal of Psychological Research, 4(2), 20-29.

reinforcer (GOOD). Bottom right: positive punisher "NO, you committed $x$ errors. The maximum allowed is $y$ "
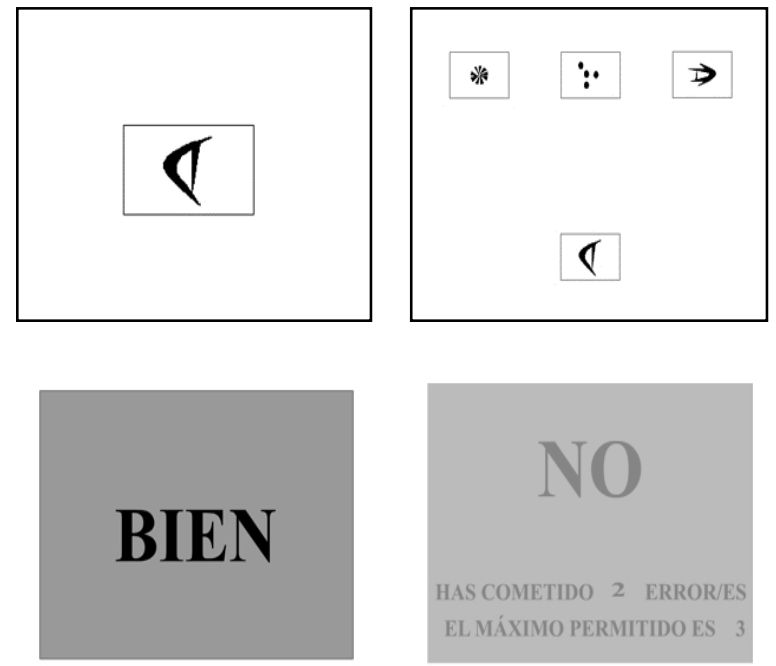

Procedure

The procedure was designed to be completed in less than one hour, and never took more than 50 - 60 minutes. Participants were individually placed in isolated desks in front of a computer. The following instructions (in Spanish) were presented:

\section{FIRST, WE WOULD LIKE TO THANK YOU FOR PARTICIPATING IN THIS STUDY \\ WE WOULD ALSO LIKE TO REMIND YOU OF THE FOLLOWING: \\ - THIS IS NOT AN INTELLIGENCE TEST \\ - THIS IS NOT A PERSONALITY TEST \\ - THIS IS NOT A TEST OF SPEED, YOU MAY TAKE AS LONG AS YOU NEED \\ - USE ONLY THE LEFT MOUSE BUTTON, DO NOT USE THE KEYBOARD OR THE RIGHT MOUSE BUTTON \\ A SERIES OF STIMULI WILL NOW} APPEAR ON THE MONITOR. A SAMPLE WILL ALWAYS APPEAR FIRST, WHICH YOU MUST CLICK ON. SOME POSSIBLE RESPONSE OPTIONS WILL THEN APPEAR ON THE TOP OF THE SCREEN. YOU MUST CLICK ON WHICHEVER YOU THINK IS CORRECT.

The structure of the experiment had four steps: 1) Conditional discrimination training and equivalence test. 2) Eq-Eq evaluation: Subjects passing this test finished the experiment. Otherwise, they advanced to the next phase. 3) Facilitation procedure (see below). 4) Second Eq-Eq evaluation. 
International Journal of Psychological Research, 2011. Vol. 4. No. 2. ISSN impresa (printed) 2011-2084

ISSN electrónica (electronic) 2011-2079

\section{Conditional discrimination training and equivalence evaluation.}

A "one-to-many" procedure was used, with "A" stimuli working as node. Training consisted of a block where A-B matching was reinforced (A1-B1, A2-B2 and A3-B3); next, A-C relations (A1-C1, A2-C2 and A3-C3) were reinforced in a separate block, and then a mixed block combining A-B and A-C relations. The first two blocks consisted of 21 trials each, and only three errors were permitted $(86 \%$ correct). If four errors or more were committed, the block was repeated. The third block mixed 18 A-B training trials and $18 \mathrm{~A}-\mathrm{C}$ trials. The learning criterion was two errors or less ( $88 \%$ correct). After passing the three training blocks, a partial equivalence test was presented. Derived C-B conditional discriminations were assessed (C1-B1, C2-B2 and C3-B3). This block consisted of 15 non-reinforced trials where $\mathrm{C} 1, \mathrm{C} 2$ or $\mathrm{C} 3$ were the samples and B1, B2 and B3 as comparisons. The criterion fixed to pass this test was 2 errors or less (86\% correct); then, the participant advanced to the Eq-Eq evaluation phase.

\section{First Eq-Eq evaluation}

This block was composed of 36 trials. Two equivalent stimuli formed the sample in half of the trials, and two non-equivalent stimuli in the other half. One of the comparisons was formed by equivalent stimuli and the other by non-equivalent ones. Figure 3 shows an example of each type of trial.

If the participant responded in accordance with the $\mathrm{Eq}-\mathrm{Eq}$
Perez, V., Garcia, A., \& Gomez, J. (2011). Facilitation of the equivalence equivalence responding: generalization of relational responses. International Journal of Psychological Research, 4(2), 20-29.

criterion $(86 \%$ correct) the experiment ended. In case the subject did not reach the criterion, he/she was exposed to the facilitation procedure

Figure 3. Experiment 1. Examples of equivalence equivalence and no-equivalence (NoEQ) test trials (without feedback). Left: In the presence of an equivalent sample (EQ), choosing an equivalent comparison was considered correct; right: in the presence of a non-equivalent sample (NoEq), choosing a non-equivalent comparison was considered correct.

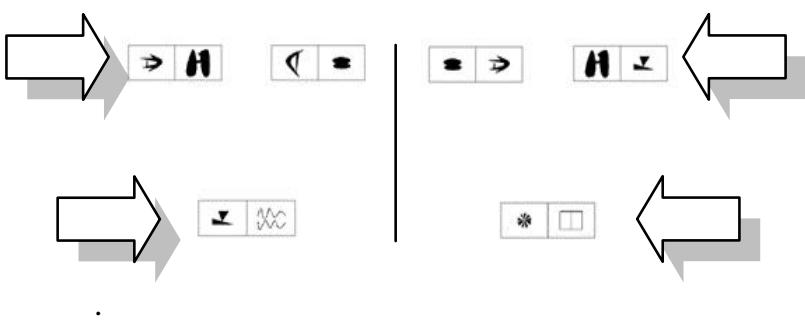

Facilitation procedure 1: Discrimination of relations

DR consisted of 24 trials, were participants were reinforced for matching a cross with a compound stimuli whose elements maintained either a physical or equivalence relation (depending on the experimental condition), and a circle with a compound stimuli whose elements were either physically dissimilar or non-equivalent. The feedback provided was the same as described for the simple conditional discrimination training. The learning criterion was fixed in a maximum of two errors; if more errors occurred, the block was repeated. Figure 4 shows an example of a trial for each condition.

Figure 4. Experiment 1. From right to left, examples of training trials in conditions : arbitrary compound sample (bottom) and simple comparisons (top); DRb: simple sample (bottom) and arbitrary compound comparisons (top); DRc: nonarbitrary compound sample (bottom) and simple comparisons (top); and DRd: simple sample (bottom) and non-arbitrary compound comparisons (top).

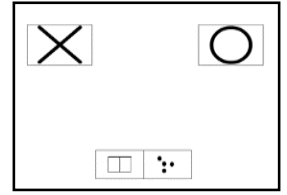

$\mathrm{DRa}$

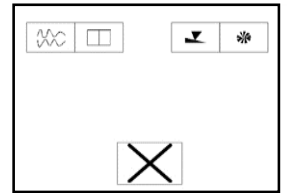

$\mathrm{DRb}$

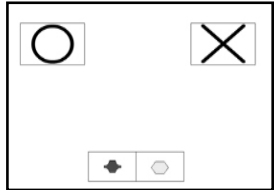

$\mathrm{DRc}$

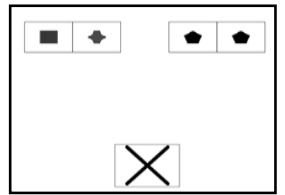

DRd
Participants passing DR were tested for Eq-Eq again, and the experiment ended.

\section{RESULTS}

All 54 participants passed the conditional discrimination training necessary to derive equivalence classes and also the C-B evaluation block. Eight (14.8\%) passed the Eq-Eq test in the first attempt. Forty six participants failed the first test, and 14 of them (25.9\%) did not pass DR training (3 in DRa, 6 in DRb, 3 in DRc and 2 in DRd); Of 36 valid participants, thirteen (41\%) correctly learnt the facilitation procedure but did not reach the criterion in the second $\mathrm{Eq}-\mathrm{Eq}$ evaluation (1/8 in DRa, 2/8 in $\mathrm{DRb}, 6 / 8$ in DRc and 4/8 in DRd); nineteen participants (59\%) learnt the facilitation procedure and also passed the 
International Journal of Psychological Research, 2011. Vol. 4. No. 2.

ISSN impresa (printed) 2011-2084

ISSN electrónica (electronic) 2011-2079

second Eq-Eq test (7 in DRa, 6 in DRb, 2 in DRc and 4 in $\mathrm{DRd})$. Since requirements for parametric tests were not met, non-parametric tests were used. The Kruskal-Wallis test showed no significant difference among conditions in pretest $(X=6.39, p>0,05)$. Figure 5 resumes these results.

Figure 5. Experiment 1. Results in both Eq-Eq evaluations (EQEQ1 and EQEQ2) per experimental condition
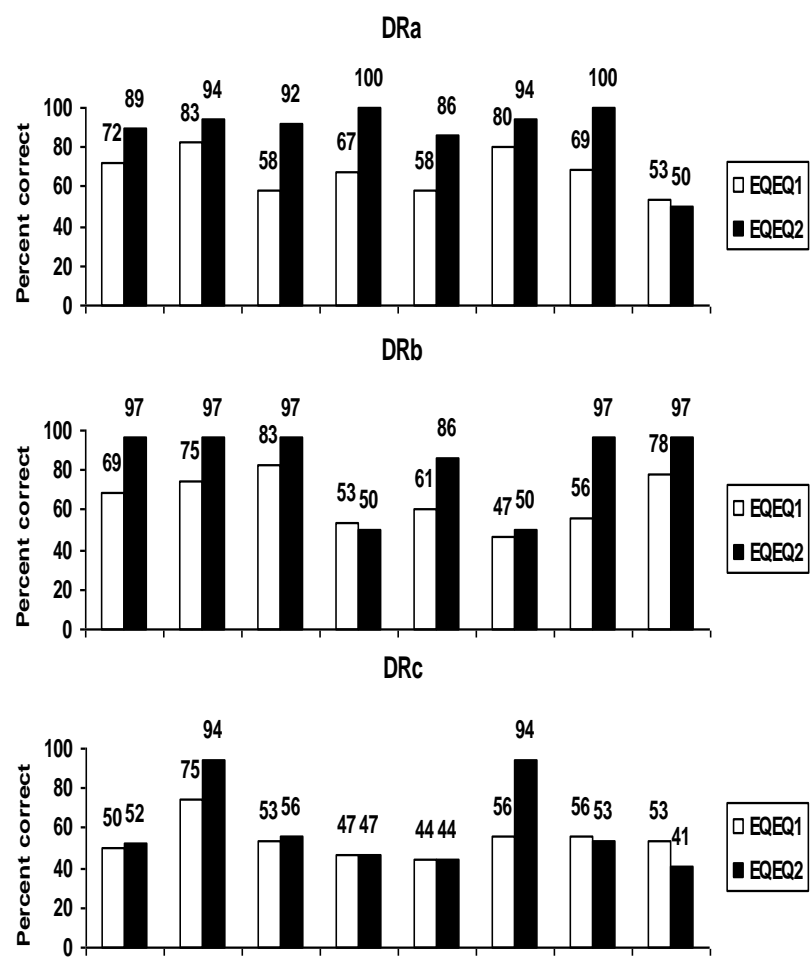

DRd

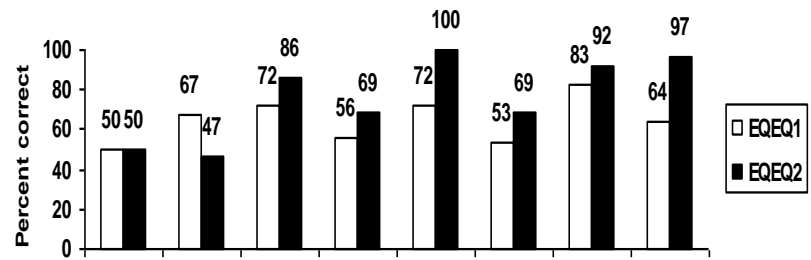

I

The Wilcoxon matched pairs test showed a significant increase in the number of hits in the second EqEq test for all participants $(Z=3.92, p<0,001)$. There were also differences among experimental conditions in the average increase of hits (7.37 in DRa, 5 in $\mathrm{DRb}, 3.75$ in DRc and 3.5 in DRd). A Kruskal-Wallis test showed differences between groups including arbitrary relations (DRa and $\mathrm{DRb}$ ) and groups including physical relations (DRc and DRd), $X=5,967, p<0,05$. No differences were found among groups DRa and DRc (compound stimulus in sample) and groups DRb and DRd (compound stimulus in
Perez, V., Garcia, A., \& Gomez, J. (2011). Facilitation of the equivalence equivalence responding: generalization of relational responses. International Journal of Psychological Research, 4(2), 20-29.

comparison). Differences between groups were also remarkable in the number of participants reaching the criterion in the second test $(7 / 8$ and $6 / 8$ in $\mathrm{DRa}$ and $\mathrm{DRb}$ and $2 / 8$ and $4 / 8$ in DRc and DRd).

\section{DISCUSSION}

All four procedures increased the number of participants successfully passing the second Eq-Eq test. A possible alternative explanation, the effect of repeated testing (Pérez \& García, 2009, 2010) was discarded in a previous study (Pérez et al., 2011). Besides, this explanation does not account for the different results obtained in the experimental conditions. Participants exposed to arbitrary relations (DRa and $\mathrm{DRb}$ ) performed better in the second Eq-Eq test than participants exposed to non-arbitrary relations (DRc and DRd) in different dependent variables, as mean number of hits and number of participants passing the test. The improvement found in groups DRc and DRd was comparable with that found in (Pérez et al., 2011, Experiment 2), where participants were also exposed to a different set of non-arbitrary relations before the second Eq-Eq test. A relational element (in either sample or comparison) seems to be enough to increase relational control. Procedures involving reinforcement contingent with the arbitrary relations of samples (DRa) or comparisons $(\mathrm{DRb})$ appeared to increase the probability that these relations became the discriminative event in the subsequent Eq-Eq test to a greater extent than non-arbitrary relations. Regarding the role of simple or complex stimulus as sample or comparisons (DRa and DRc vs DRb and DRd), differences in post-test average number of hits were small and no definitive conclusions can be derived.

\section{EXPERIMENT 2}

The main objective of this experiment was to add further evidence of stimulus generalization in $\mathrm{Eq}-\mathrm{Eq}$ responding and test the effect of relating sample and comparison relations. However, the design of this facilitation procedure allowed us to address another question: should we expect differences regarding the function of arbitrary relations as sample or comparisons? With that aim, the design of this experiment included two conditions where physical and arbitrary relations among members of complex stimuli acted either as samples or comparisons. The facilitation procedure used was called "Mixed Conditional Discrimination" (MIX, with two variants: MIXa and MIXb).

\section{METHOD}

\section{Participants}

Thirty nine participants were involved in this experiment, 31 women and 8 men, ranging from 20 to 50 
International Journal of Psychological Research, 2011. Vol. 4. No. 2.

ISSN impresa (printed) 2011-2084

ISSN electrónica (electronic) 2011-2079

years of age $($ mean $=34.92 ;$ standard deviation $=8.53)$. They all were volunteer university students and had no previous knowledge of the purpose of the experiment. Participants were randomly assigned to two conditions: 10 to condition MIXa (3 men, 7 women) and 29 to condition MIXb (5 men, 24 women).

Apparatus and stimuli.

The same as in Experiment 1.

\section{Procedure}

The general procedure used was the same as in Experiment 1, except for the mixed conditional discrimination facilitation procedure included between the first and second $\mathrm{Eq}-\mathrm{Eq}$ evaluation.

\section{Facilitation procedure 2: Mixed Conditional Discrimination}

This training block was composed by 24 trials with a complex sample and two complex comparisons. The learning criterion to pass the training phase was two errors or less. Condition MIXa had a compound sample with two equivalent or non-equivalent stimuli, and two compound comparisons, one with physically identical stimuli and the other with physically different stimuli. Matching equivalent sample stimuli with physically identical stimuli was reinforced, as well as matching non-equivalent stimuli with physically dissimilar stimuli. In condition MIXb, stimuli holding a non-arbitrary relation worked as sample, while equivalent or non-equivalent stimuli acted as comparisons. Figure 6 shows a trial of each procedure.

Figure 6. Experiment 2. From right to left, examples of training trials in conditions MIXa: arbitrary compound sample (bottom) and non arbitrary compound comparisons ( top); and MIXb: non-arbitrary compound sample (bottom) and arbitrary compound comparisons (top).

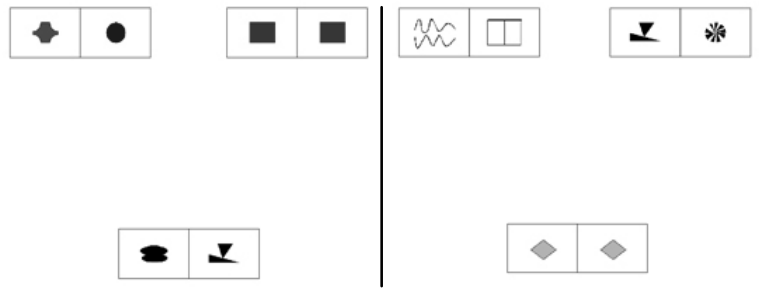

RESULTS

All participants passed the conditional discrimination training necessary to derive equivalence classes and also the C-B evaluation block. Twelve of 39
Perez, V., Garcia, A., \& Gomez, J. (2011). Facilitation of the equivalence equivalence responding: generalization of relational responses. International Journal of Psychological Research, 4(2), 20-29.

participants $(30.8 \%)$ reached the criterion in the first $\mathrm{Eq}-\mathrm{Eq}$ evaluation, and the experiment ended for them. Of the remaining 27 participants, $11(40.7 \%)$ did not learn the facilitation procedure (all in condition MIXb). A KruskalWallis test showed no significant differences in the first Eq$\mathrm{Eq}$ evaluation for 16 valid participants in both groups ( $X=0.07, p>0.05)$. However, the Wilcoxon test showed significant differences between the first and the second Eq$\mathrm{Eq}$ evaluation for both groups $(Z=3.42, p<0.001)$. Two participants $(12.5 \%)$ passed the facilitation procedure but did not reach the criterion in the second Eq-Eq test (both in condition MIXa). Finally, $14 / 16$ participants $(87.5 \%)$ correctly learned the facilitation procedure and passed the second Eq-Eq evaluation (6/8 in MIXa and 8/8 in MIXb). The average increase of hits in was 9.62 in MIXa (standard deviation $=7.65$ ) and 12 in $\mathrm{MIXb}$ (standard deviation = 4.40). No differences between groups were found $(X=0.942$, $p>0.05$ ). Figure 7 resumes these results.

Figure 7. Experiment 2. Results in both Eq-Eq evaluations (EQEQ1 and EQEQ2) per experimental condition.
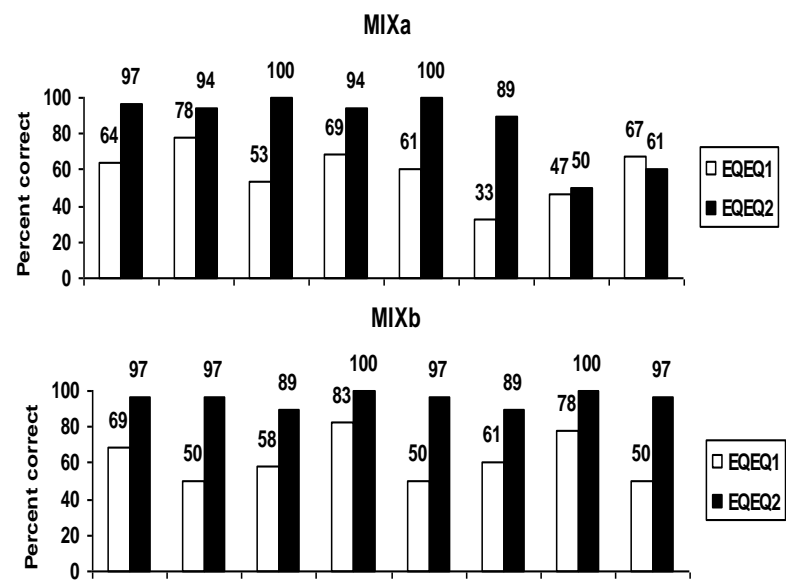

\section{DISCUSSION}

Facilitation procedures MIXa and MIXb improved performance in the second $\mathrm{Eq}-\mathrm{Eq}$ evaluation, both measured in average number of hits and number of participants passing the test. Procedures MIXa and MIXb were similar to the "Same / Different" (S/D) facilitation procedure used in Pérez et al., (2011, Experiment 2), where complex stimuli were used as sample and comparison, although only physical relations were used in that case. Only $40.6 \%$ participants in that experiment passed the second Eq-Eq test, while $87.5 \%$ and $100 \%$ passed in the present experiment. The training situation in this experiment included arbitrary relations as either sample or comparison, and thus it shared more similarities with the $\mathrm{Eq}-\mathrm{Eq}$ test situation, and generalization was more readily observed. As in Experiment 1 the presence of arbitrary 
International Journal of Psychological Research, 2011. Vol. 4. No. 2. ISSN impresa (printed) 2011-2084

ISSN electrónica (electronic) 2011-2079

relations significantly improved Eq-Eq responding regardless of its role as sample or comparisons.

\section{GENERAL DISCUSSION}

Taken together, these experiments appear to support our original hypothesis: the efficacy of the facilitation procedures increased as the number of features in common with the Eq-Eq test did so. Thus, generalization
Perez, V., Garcia, A., \& Gomez, J. (2011). Facilitation of the equivalence equivalence responding: generalization of relational responses. International Journal of Psychological Research, 4(2), 20-29.

Table 1. Percentage of valid participants ( 8 per condition) passing the facilitation procedures and the second Eq-Eq evaluation, and mean increment of hits (in parenthesis). A-A, A-B, A-C was tested in (Pérez, 2007); S/D: "Same / Different" was tested in Pérez et. al. (2011); DR: "Discrimination of Relations", MIX: "Mixed Conditional Discrimination"; EQEQ: Equivalence - Equivalence. Asterisks indicate statistically non significant effects. The number in italics is the number of participants failing each facilitation procedure.

\begin{tabular}{|c|c|c|c|c|c|}
\hline & \multicolumn{3}{|c|}{ COMPARISONS } \\
\hline & & & \multirow[t]{2}{*}{ Simple } & \multicolumn{2}{|c|}{ Compound } \\
\hline & & & & Non-arbitrary & Arbitrary \\
\hline \multirow{3}{*}{ SAMPLE } & \multicolumn{2}{|c|}{ Simple } & $\mathrm{A}-\mathrm{A}, \mathrm{A}-\mathrm{B}, \mathrm{A}-\mathrm{C}-\mathrm{O}$ & DRd - 4 & $\mathrm{DRb}-6$ \\
\hline & \multirow{2}{*}{$\begin{array}{l}\text { Com- } \\
\text { pound }\end{array}$} & $\begin{array}{l}\text { Non- } \\
\text { arbitrary }\end{array}$ & 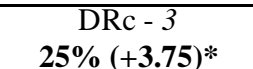 & $\begin{array}{c}\mathrm{S} / \mathrm{D}-0 \\
\mathbf{4 0 . 6 \%}(\mathbf{+ 5 . 9 3})\end{array}$ & $\begin{array}{l}\text { MIXb - 11 } \\
100 \%(+\mathbf{1 2})\end{array}$ \\
\hline & & Arbitrary & $\begin{array}{c}\text { DRa - 3 } \\
\mathbf{8 7 . 5 \%}(+\mathbf{7 . 3 7})\end{array}$ & $\begin{array}{c}\text { MIXa - } 2 \\
\mathbf{7 5 \%}(\mathbf{+ 9 . 6 )}\end{array}$ & EQEQ \\
\hline
\end{tabular}

Exposition to baseline training (Pérez, 2007) or to a distraction task (Pérez et al., 2011, Experiment 1), produced no improvement. Relational tasks involving non-arbitrary stimuli (DRc, DRd, Experiment 1), and the same/different task (S/D, Pérez et al., 2011, Experiment 2; Pérez et al., 2004), produced a moderate improvement. Major improvement was found when arbitrary relations appeared as either sample or comparisons (DRa, DRb, MIXa, MIXb). MIX procedures appeared to show a slightly higher improvement than DRa and DRb in terms of mean number of hits, but it was statistically non-significant. Thus, the most relevant factor in $\mathrm{Eq}-\mathrm{Eq}$ improvement was the addition of relational elements in either sample comparisons, or both. Non-arbitrary relations produced moderate improvement; while arbitrary relations leaded to better scores (even 100\% in some conditions). These results add further support to the hypothesis of Eq-Eq as a generalised or overarching operant under the control of discriminative stimuli. Explicitly relating compound relations (MIXa and MIXb; S/D) was not as important as the presence of arbitrary relations (DRa and $\mathrm{DRb}$ ). At the same time, results stress the relevance of the relational properties of stimuli as discriminative in $\mathrm{Eq}-\mathrm{Eq}$ responding and probably in analogical reasoning.

But facilitation procedures showed also differences in difficulty. Although these experiments were not designed to systematically analyze the difficulty of facilitation procedures, Table 1 appears to show a pattern. Increments in sample complexity from simple to non-arbitrary and within functionally defined stimulus classes has been clearly demonstrated. Table 1 summarizes the results of these and similar experiments showing generalization from facilitation procedures to Eq-Eq test as a function of its common features, as well as its difficulty (number of participants failing to pass the facilitation procedure in the programmed number of trials). arbitrary relations (DRc, DRa, MIXa) do not seem to increase difficulty. But as comparison complexity increases (DRd, DRb, MIXb), more participants fail to learn the procedure in the programmed number of trials. Since an increased probability of relational stimulus control in either sample or comparisons appears to be enough to foster relational stimulus control, a possible explanation is that complex comparisons could increment the number of idiosyncratic relations among stimuli competing with the experimenter - defined relevant features of the task as preliminary found in Pérez (2007). Although highly speculative at the time, this hypothesis could be empirically tested in future experiments. The analysis of the verbal behaviour of participants during training and testing situations has been successfully applied to equivalence class formation (e. g. Cabello, Luciano, Gomez, \& BarnesHolmes, 2004; Moreno, Tena, Larios, Cepeda, Hickman, Plancarte, Arroyo, \& Cerutti, 2008; Wulfert, Dougher, \& Greenway, 1991). Extending these methods to Eq-Eq responding experiments when participants are exposed to the arbitrary and non-arbitrary samples and comparisons of the different facilitation procedures could provide relevant insights to our understanding of this complex ability.

\section{REFERENCES}

Barnes, D., Hegarty, N., \& Smeets, P. M. (1997). Relating equivalence relations to equivalence relations: A relational framing model of complex human 
International Journal of Psychological Research, 2011. Vol. 4. No. 2.

ISSN impresa (printed) 2011-2084

ISSN electrónica (electronic) 2011-2079

functioning. Analysis of Verbal Behavior, 14, 5783.

Bohórquez, C., García, A., Gutiérrez, M. T., Gómez, J., y Pérez, V. (2002). Efecto del entrenamiento en reflexividad y la evaluación de equivalencia en la competencia entre relaciones arbitrarias y no arbitrarias en el paradigma equivalenciaequivalencia. International Journal of Psychology \& Psychological Therapy, 2(1), 41-56.

Cabello, F., Luciano, C., Gomez, I., \& Barnes-Holmes, D. (2004). Human schedule performance, protocol analysis, and the 'silent dog' methodology. The Psychological Record, 54(3), 405-422.

Carpentier, F., Smeets, P. M., \& Barnes-Holmes, D. (2002). Matching functionally same relations: Implications for equivalence-equivalence as a model for analogical reasoning. The Psychological Record, 52(3), 351-370.

Carpentier, F., Smeets, P. M., \& Barnes-Holmes, D. (2003). Equivalence-equivalence as a model of analogy: Further analyses. Psychological Record, 53(3), 349-371.

García, A., Bohórquez, C., Gómez, J., Gutiérrez, M. T., y Pérez, V. (2001). Ensombrecimiento entre relaciones arbitrarias y no arbitrarias en el paradigma de equivalencia-equivalencia. Summa Psicológica, 8(2), 251-270.

García, A., Bohórquez, C., Pérez, V., Gutiérrez, M. T., \& Gómez, J. (2008). Equivalence-equivalence responding: Training conditions involved in obtaining a stable baseline performance. The Psychological Record, 58(4), 597-622.

García, A., Gómez, J., Pérez, V., Bohórquez, C., y Gutiérrez, M. T. (2003). Efectos de orden de presentación entre criterios de respuestas basados en relaciones de semejanza y de equivalenciaequivalencia. Acción Psicológica, 2(3), 239-249.

García, A., Gutiérrez, M. T., Bohórquez, C., Gómez, J., y Pérez, V. (2002). Competencia entre relaciones arbitrarias y relaciones no arbitrarias en el paradigma de equivalencia-equivalencia. Apuntes de Psicología, 20(2), 205-224.

García, A., Pérez, F., Martín, Gutiérrez, M. T., Benjumea, S., Gómez, J., y Pérez, V. (2011) Efecto de la edad y el tipo de reforzador en la equivalenciaequivalencia mediante un procedimiento de partición. International Journal of Psychological Research. 4(1), 7-15.

Gómez, J., García, A., Pérez, V., Gutiérrez, M. T., y Bohórquez, C. (2004). Aportaciones del análisis conductual al estudio de la conducta emergente: algunos fenómenos experimentales. Revista Internacional de Psicología y Terapia Psicológica, 4(1), 161-191.

Hayes, S. C. \& Barnes-Holmes, D. (2004). Relational operants: Processes and implications: A response
Perez, V., Garcia, A., \& Gomez, J. (2011). Facilitation of the equivalence equivalence responding: generalization of relational responses. International Journal of Psychological Research, 4(2), 20-29.

to Palmer's review of relational frame theory. Journal of the Experimental Analysis of Behavior, 82(2), 213-224.

Hayes, S. C., Barnes-Holmes, D., \& Roche, B. (2001). Relational frame theory: A post-Skinnerian account of human language and cognition. New York, NY US: Kluwer Academic/Plenum Publishers.

Hayes, S. C., Gifford, E. V., \& Wilson, K. G. (1996). Stimulus classes and stimulus relations: Arbitrarily applicable relational responding as an operant. In T. R. Zentall \& P. M. Smeets (Eds.), Stimulus class formation in humans and animals. (pp. 279299). New York, NY US: Elsevier Science.

Horne, P. J. \& Lowe, C. F. (1996). On the origins of naming and other symbolic behavior. Journal of the Experimental Analysis of Behavior, 65(1), 185.

Lipkens, R. \& Hayes, S. C. (2009). Producing and recognizing analogical relations. Journal of the Experimental Analysis of Behavior, 91(1), 105126.

Luciano, M. C. \& Gómez, S. (2001). Derivación de funciones psicológicas. Psicothema, 13(4), 700707.

Markham, M. R. \& Dougher, M. J. (1993). Compound stimuli in emergent stimulus relations: Extending the scope of stimulus equivalence. Journal of the Experimental Analysis of Behavior, 60(3), 529542.

Moreno, D., Tena, O., Larios, R. M., Cepeda, M. L., Hickman, H., Plancarte, P., ... Cerutti, D. (2008). Effects of Trial-Specific Verbal Descriptions on Matching-to-Sample Performances of Children and Adults. European Journal of Behavior Analysis, 9, 29-42.

O'Toole, C., Barnes-Holmes, D., Murphy, C., O'Connor, J., \& Barnes-Holmes, Y. (2009). Relational flexibility and human intelligence: Extending the remit of Skinner's Verbal Behavior. International Journal of Psychology \& Psychological Therapy, 9(1), 117.

Pérez-González, L. A. (1994). Transfer of relational stimulus control in conditional discriminations. Journal of the Experimental Analysis of Behavior, 61(3), 487-503.

Pérez, V. (2007). Generalización de la respuesta controlada por relaciones arbitrarias entre estímulos. Universidad Nacional de Educación a Distancia, Madrid.

Pérez, V. \& García, A. (2009). Aprendizaje sin refuerzo explícito en discriminaciones condicionales con estímulos complejos. Revista Latinoamericana de Psicología, 41(1), 59-68.

Pérez, V. \& García, A. (2010). Contingencias de aprendizaje sin refuerzo explícito. Psicothema, 22(3), 416-423.

International Journal of Psychological Research 
International Journal of Psychological Research, 2011. Vol. 4. No. 2.

ISSN impresa (printed) 2011-2084

ISSN electrónica (electronic) 2011-2079

Pérez, V., García, A., \& Gómez, J. (2011). Facilitation of the Equivalence - Equivalence response. Psicothema, 23(3), 407-414.

Pérez, V., García, A., Gómez, J., Bohórquez, C., y Gutiérrez, M. T. (2004). Facilitación de la respuesta de equivalencia-equivalencia en niños. Revista Mexicana de Análisis de la Conducta, 30(1), 93-107.

Ruiz, F. J. \& Luciano, M. C. (2011). Cross-domain analogies as relating derived relations among two separate relational networks. Journal of the Experimental Analysis of Behavior, 95, 369-385.

Sidman, M. (1971). Reading and auditory-visual equivalences. Journal of Speech \& Hearing Research, 14(1), 5-13.

Sidman, M. (1994). Equivalence relations and behavior: A research story. Boston, MA US: Authors Cooperative.

Sidman, M. \& Tailby, W. (1982). Conditional discrimination vs. matching to sample: An expansion of the testing paradigm. Journal of the Experimental Analysis of Behavior, 37(1), 5-22.

Skinner, B. F. (1938). The behavior of organisms: an experimental analysis. Oxford England: AppletonCentury.

Stewart, I. \& Barnes-Holmes, D. (2004). Relational Frame Theory and Analogical Reasoning: Empirical Investigations. International Journal of Psychology \& Psychological Therapy, 4(2), 241262.

Stewart, I. \& Barnes-Holmes, D. (2009). Training analogical reasoning as relational responding. In A. Rehfeldt \& Y. Barnes-Holmes (Eds.), Derived Relational Responding: Applications for Learners with Autism and other Developmental Disabilities. Oakland, CA: New Harbinger.

Stewart, I., Barnes-Holmes, D., Roche, B., \& Smeets, P. M. (2001). Generating derived relational networks via the abstraction of common physical properties: A possible model of analogical reasoning. Psychological Record, 51(3), 381-408.

Stewart, I., Barnes-Holmes, D., Roche, B., \& Smeets, P. M. (2002a). A functional-analytic model of analogy: A relational frame analysis. Journal of the Experimental Analysis of Behavior, 78(3), 375396.

Stewart, I., Barnes-Holmes, D., Roche, B., \& Smeets, P. M. (2002b). Stimulus equivalence and nonarbitrary relations. Psychological Record, 52(1), 77-88.

Stromer, R. \& Stromer, J. B. (1990). Matching to complex samples: Further study of arbitrary stimulus classes. Psychological Record, 40(4), 505-516.

Sweeney, M. M. \& Urcuioli, P. (2010). Reflexivity in pigeons. Journal of the Experimental Analysis of Behavior, 94, 267-282.
Perez, V., Garcia, A., \& Gomez, J. (2011). Facilitation of the equivalence equivalence responding: generalization of relational responses. International Journal of Psychological Research, 4(2), 20-29.

Vasconcelos, M. (2008). Transitive inference in non-human animals: An empirical and theoretical analysis. Behavioural Processes, 78(3), 313-334.

Wright, A. A. \& Katz, J. S. (2007). Generalization hypothesis of abstract-concept learning: Learning strategies and related issues in Macaca mulatta, Cebus apella, and Columba livia. Journal of Comparative Psychology, 121(4), 387-397.

Wulfert, E., Dougher, M. J., \& Greenway, D. E. (1991). Protocol analysis of the correspondence of verbal behavior and equivalence class formation. Journal of the Experimental Analysis of Behavior, 56(3), 489-504. 